paper, giving the results of a bacteriological examination of 198 cases of cholera. In these cases they found the bacillus virgula abundant in 20, moderately abundant in 107, in small numbers and difficult to find in 24 , and absent in 45 . In the 45 cases in which no comma bacillus was found, the bacterium coli commune was found alone in 15; associated with staphylococci, streptococci, or rarely the B. pyocyaneus in 30.

Protective inoculation might be said to have some bearing on the question of diagnosis, but the evidence obtained by the work of Ferrán, Gamaleïa, Haffkine, Klemperer, Klein, Metchnikoff, Pawlowsky, and Buchstab, etc., is of a nature which does not encourage reliance on such a method of diagnosis at the present time.

\section{General Conclustons.}

Although I am fully aware of the objections which Koch might offer, and has indeed offered, to some of the observations related above, it seems to me that the following conclusions can hardly be avoided:-

1. It is as yet impossible to speak dogmatically of the infallibility of the bacteriological diagnosis of cholera Asiatica.

2 . All the more recent observations point to the importance of the contamination of water and soil with dejecta as a cause of outbreaks of cholera similar to Indian cholera.

3 . These recent observations undoubtedly lend much support to the localistic views of Cunningham and of Pettenkofer, though in their details these views may have to be modified.

Nore.-It is evident that until it is possible to speak more positively, the bacteriological examination will have to be conducted with even more care than it has been hitherto, as only in this way will it be possible to remove all the doubts that remain.

\section{REFERENCES.}

1 Koch, Semaine Nelicale, May 31st, 1893, p. 265. 2 Medical Chronicle, 1893, xviii, p. 323. Regarding this see also Klemperer, Medical Chronicle, $\mathrm{xix}, \mathrm{p} .37 .{ }^{3}$ Loc. cit. $4 \mathrm{Koch}$, The Etiology of Cholera, Microparasites in Disease, New Sydenham Society, p. 329. 3 Zeitschrift für Hygiene und Intec rons-Krankheiten, vol. xiv, Nơ. 2, 1893; Semaine Médicale, May, 1893, p. 265: Practitioner, 1893, vol. li, p. 471; BRITISH MEDICAL JouRNAL, June 17th, 1893. 'Semaine Médicale, 1893, p. 267. 7 Scientific Memoirs by the Medical Officer, etc., Calcutta, 1891. ${ }^{8}$ Annales de l'Institut Pasteur, 1893, p. 554. Annales de Institut Pasteur, 1893, p. 562. 10 Zeitschr. f. Hyg. 1887 ; Annales de l'Institut Pasteur, 1838, pp. 30-45; regarding the cholera red reaction, see Jadassohn, ibid, 1883. p. 44. 11 Annales de l'Institut Pasteur, October', 1893, p. 689. '12 Ibid., p. 693. 13 Hygienische Rundschau, August, 1893, p. 160. ${ }^{16}$ Annales de l'Institut Pasteur, January 25th, 1893, p. 18.

\section{REMARKS ON THE TREATMENT OF PERITONITIS BY DRAINAGE,}

WITH ILLUSTRATIVE CASES,

By GILBERT BARLING, M.B., F.R.C.S.,

Professor of Surgery in Mason College, and Surgeon to the General Hospital, Birmingham.

During the last eighteen months a series of most interesting cases of peritonitis has fallen under my care, all of which were treated by drainage. They illustrate several points of importance in etiology, treatment, and prognosis. The cases, ten in number, include two of acute sero-purulent peritonitis, five of purulent peritonitis, and three which were tuberculous. Some of these have already been described in full ${ }^{1}$ and only the main features will here be presented for the purpose of summary.

In reviewing these cases the first point of interest is to inquire if they throw any light upon the etiology of peritonitis. Cases I and II were so similar in their onset, in the ages of the patients, in the inflammatory material produced, and in the absence of a local lesion to explain the attacks, that they were both regarded as cases of acute peritonitis, such as is sometimes described as rheumatic or jdiopathic in origin. The subsequent fatal seizure in Case II provided positive proof that acute inflammatory lesions of the vermiform appendix were the cause of both attacks of peritonitis in this patient. That this organ might be the starting point of the trouble was ever present to my mind, as I have been in the habit of pressing the importance of appendicitis on students in my classes for years. For this reason the presence of a local inflammatory collection in the right iliac

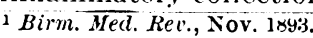

fossa was especially sought for, but none could be made out, even under anæsthesia. This may have been due to the rigidity and distension of the abdomen, but it emphasises a point insisted upon in a paper of mine read at the annual meeting of the Association, ${ }^{2}$ that not a few cases of acute perforative appendicitis are latent as far as the local lesion is concerned. The revelation of the cause of the peritonitis in Case II throws considerable doubt on the assumed idiopathic origin of Case $I$, although there was in this a definite exposure to extreme cold, which appeared to account for the seizure. Whilst willing to concede this as a probable example of perforative rather than idiopathic peritonitis, I am certainly not prepared to give up the latter term as mythical. Using the term in its ordinary sense to indicate that no. definite local lesion can be recognised as the cause, such as perforation or hæmorrhage, nor any specific poison such as that of tuberculosis, I have no doubt that we have at times in the abdomen, as in the thorax, an acute catarrhal inflammation of the serous membrane, which, as in the thorax, may become purulent. Such a condition is illustrated, I believe, in Case III, and it is probable that in such the inflammatory process is initiated by exposure to cold and overfatigue, whilst the subsequent purulent change is due to the grafting of pyogenic organisms on to what was before a simple non-infective condition. The focus from which invasion takes place is not far to seek, seeing that the inflamed membrane is so intimately related to the intestinal tract. In. Case IV it is probable that the long-standing sinus leading to the left iliac fossa was due to a caseating tuberculous gland, which, by bursting into the peritoneal cavity, set up a localised suppurative peritonitis. A definite thickening of small area was present here for some months, and curdy caseous material could constantly be squeezed out of the sinus.

The result of the treatment by abdominal section is, I think, satisfactory, despite the fact that four deaths have to. be recorded after eleven operations. Case Ix died within a week, of disease so extensive and generalised that relief by any treatment was hopeless. Case vi died at the end of a month after the second operation, and it is impossible to decide what part the operation had in causing the extensive and widespread suppurations in the abdomen, and which of these were due to the original peritonitis. My experience of suppurations below the diaphragm, but in the upper part of the abdomen, is that they are very anxious conditions to. interfere with, and are peculiarly liable to end in septicæmia. The third case dying, No. $x$, was tuberculous in its origin, and several weeks after the abdomen was opened a fæcal fistula formed. This was the cause of the child's death, but it would! not be fair to ascribe this without doubt to the abdominal, section, as the same condition is recognised as a naturali termination produced by the disease. It is, however, worth. considering as a possible bad result of operative interference. in tuberculous cases, seeing that the breaking down of adhesions, sometimes necessary, may weaken the intestinal wall, and that infection by ordinary pus cocci may take place, leading to more rapid spread of the tuberculous process. The. remaining fatality, in Case II, was extremely disappointing. The first operation on this patient ended in apparent complete recovery, he having been at work for some months. before his second attack of peritonitis. Four days before this: came on he presented himself for examination, and seemed in robust health, and though at this time a careful examina-tion was made of his abdomen no thickening or tenderness. could be felt anywhere.

CASE I. Acute Sero-purulent Peritonitis ; Drainage; Recovery.-N.N.., male,. aged 20 , was first seen in consultation, January 28 th, 1893 . with Drs.. Simon and Middleton. On January 21 st he complained of feeling poorly,. and this continued for three or four days, but on January $26 \mathrm{th}$ he felt so. and this continued for three or four days, but on January 26 th he felt so.
much better that he thought of resuming his work. Later on this day,much better that he thought of resuming his work. Later on this day,however, he had severe griping pain in the abdomen, and on January. His pulse was then 120 , temperature $101^{\circ}$, he was vomiting, his abdomen was distended, rigid, and tender, his facial expression was bad; the. bowels were constipated both for flatus and fæces. On January 28 th. when I saw him, his condition was very much the same, except that the: pulse was quicker and very small. The vomit was coffee coloured. A. pulse was quick quantity of fæces had been passed, together with fluid which had the character of urine, and which, as the patient positively declared it had not been passed per urethram, gave rise to the suspicion that there was a communication between the bladder and the rectum, which was

2 British Medical Journat, vol. i, 1893. 
the starting point of acute peritonitis. The subsequent history of normal urine and normal micturition in every way negatived this supposition, which was unsupported by examination of the rectum and of the onset of the illness was exposure to severe cold a day or so before its commencement.

The diagnosis of acute peritonitis, which was getting worse despite treatment, in face of the patient's critical condition, determined us upon immediate operation, and I opened the abdomen in the middle line below the umbilicus, and evacuated several ounces of fotid sero-purulent fluid from the pelvis. No focus of disease or perforation could be detected, so the abdomen was irrigated and drained. The result of the operation was at first most satisfactory, there was improvement in all operation was at first most satisfactory, there was improvement in all the symptoms, but at the end of a few days the wound gaped and looked as though it were about to become the seat of phagadæna, the quick pulse and the temperature returned. At thi

On February 14th a collection of pus in the right anterior lumbar region was evacuated through a tube introduced by the wound. At the region was evacuated through a tube introduced by the wound. At the needle was introduced into each side of the chest, but no fluid was obneedle was introduced into each side of the chest, but no fluid was ob-
tained. Following this there was slow improvement until March 10th, when the temperature again ran up and there was pain in the belly.

On March 13th a further collection of pus was found on the right side of the abdomen, at the junction of the right iliac and lumbar regions, valescence, and the patient is now in excellent health, the abdomen valescence, and the patient is now in excellen

CASE 1I. Acute Sero-purulent Peritonitis, Drainage, Recovery.-R.D., male, aged 19 , was seen on February 27 th, 1893 , in consultation with Dr. F. Hues, of Handsworth. On February 20th the patient suffered severe pain in the abdomen, and this continuing he took to his bed on February 22nd,
and was more or less of an invalid for the next five days. In addition to pain he had sickness, diarrhoa, and pain on micturition. He appears to have dieted very indiscreetly during this period. His history showed no exposure to cold, violence, or any kind of infection, but he believed that he had had attacks of pain of a similar kind before, with a swelling in the right iliac region; this in answer to a leading question. The patient's surroundings were so bad that there was little hope of treating him success fully where he was, so he was tranferred to hospital the same day.

The note of his condition on admission was, marked facies Hippocratica, pulse, 120, small ; temperature, 101 ; respiration, 30 ; violent hiccough every third breath, vomiting of greenish offensive fluid at frequent intervals, one fluid motion passed. The abdomen was distended over the lower half, very tense and tender, and respiration was thoracic. On percussion an area of absolute dulness was found occupying the left iliac and the left half of the hypogastric region. No tumour mass or fluctuation could be made out. Emptying the bladder with the catheter made no difference to the dulness. The abdomen was opened in the middle line on the day of admission (February 27th), a little above the pubes, and a quantity of stinking sero-purulent fluid was evacuated. There was no free gas or fecal particles in this, nor could any perforated organ or local focus be discovered as the starting point of the trouble. The abdomen was though interrupted for a few days by mild delirium. At the present time the patient is quite well.

The preceding note was written after the patient was examined on October 12th. On October 17 th he was readmitted to hospital with his when on heen well until October 16th, when on getting up in the morning he had pain in the abdomen and was his bowels acted freely three or four times.

October 17th. On admission late at night his abdomen was moderately distended, tender, fixed, and rigid; no special fulness or hardness could be felt in the right iliac fossa. Diminished resonance existed over the he felt in the right iliac fossa. Diminished resonance existed over the hypogastrium and both flanks; the bowels acted once. The pulse was dilated. Food by the mouth was prohibited, and nutriment was administered per rectum.

October 18th. When I first saw him in this attack the pulse was 120 soft; temperature, $98.6^{\circ}$. He had passed a very restless night, and had domen was described as less tender and tense, and the face as less domen was described as less tender and tense, and the face as less pinched. The patient expressed himself as feeling better, and this was stances, after consultation, it was considered advisable to wait before stances, after consultation, it was

October 19th. The condition was little changed, except that the facial expression was worse, and the vomiting had been very frequent, blood being present in considerable quantity in the vomit. The pulse was 114 temperature, 101.5. The tongue was dry and brown. The abdomen was now opened through the old incision. The omentum was found adherent were evacuated. The fingers searched in the right iliac fossa for any thickening or other lesion, but none was found; so, after irrigation, a tube was placed in the pelvis.

October 20th. The patient had been very delirious and violent all night, getting out of bed once despite his attendant, and the drainage tube was displaced out of his wound three times. The pulse was 120 ,
temperature $99.5^{\circ}$. The face looked very pinched, the abdomen was scarcely tender. Vomiting was much less frequent

October 21st. Again there was an account of a delirious and restless night, with occasional vomiting. Rectal feeding had to be discontinued for a time. Temperature $99^{\circ}$, pulse 128 , tongue very diy and brown, sordes on the lips. From the tube some drachms of stinking pus continued to be withdrawn. From this time the report is one of gradually failing strength, but the predominant features of the case were rather of advancing peritonitis. The patient died regarded as characteristic after the operation. The post-mortem examination was made by Dr. Stanley, whose report is as follows: On section, considerable adlesion of the great omentum to the abdominal wall and to the intestinal coils be- neath, and adhesions of the coils to each other. There was a large quantity of purulent fluid in the pelvis, and between the diaphragm and the right lobe of the liver, which was thereby displaced to the left. Round the cacum and appendix there was considerable matting, and signs of old and recent inflammation; in this tissue, and partly attaclied to the appendix, was a small concretion, about the size of a pea, and here the appendix was buried in inflammatory tissue. Nearer the crecum large as the first; this was free in the cavity of the appendix and had large as the first; this was ree in the cavity of the appendix, and had
not produced any ulcerative change around it, but the walls of the part
were greatly thickened. The communication between the cæcum and the appendix was patent. The whole of the large intestine was loaded with facal accumulation, and part of the wall of the transverse colon was so thin, that it broke down on separation of the not very firm adhesions. In the pelvis to the left was a strong adhesion embracing the rectum, and causing a sharp bend

CASE III. Suppurative Peritonitis ; Drainage : Recovery. (Summary).-Gir], aged 7 admitted to hospital May $3 r d, 1892$, after being ill for a month with fever, abdominal pain, occasional vomiting, and constipation. The illness came on after a long and exhausting walk. When admitted the abdomen was distended with fluid, the umbilicus was red and oedematous, the superficial veins were very distended. Drainage evacuated about four pints of pus, and an uninterrupted recovery followed. The child is now in robust health.

CASE Iv. Suppurative Peritonitis: Drainage; Recovery. (Summary.) Male, aged 16, admitted to hospital January 6 th, 1893, after an illness of eighteen days, during which time there was fever of from 2 to 5 degrees, pain in the abdomen at times very severe, occasional vomiting, diarrhoea time of the operation the lower part of the abdomen was rigid, tender, and dull ; no tumour could be made out. Drainage let out 6 ozs. of foetid pus, for which no exciting focus could be discovered. A sinus remained for nearly six montlis, leading to a

CAsa. The boy is now perfectly well. Recovery. (Summary.)-Girl, aged 13, admitted the Abdomen; Drainage, after an illness of five weeks' duration, which consisted in abdominal pain, chiefly on the right side, vomiting, and constipation, with loss of flesh. When operated upon a fluctuating swelling presented in the umbilical region, but above the umbilicus. Temperature $102^{\circ}$. Incision let out several ounces of pus from a cavity bounded behind by the liver and great omentum. Some peritonitis followed for a few days, but eventually months. The child is now well.

CASE vi. Localised Suppurative Peritonitis presenting in the Epigastrium; Hepatic Abscess ; Double Pyosalpinx, etc.; Drainage: Death. (Summary.)Female, aged 20, first admitted to hospital May 13th, 1893, with a fluctuating swelling presenting in the epigastrium, rigors, and high temperature behind by the stomach and liver. A sinus resulted, which at the end of July caused her readmission, as there was free discharge of pus from it. A pus-containing cavity was then found at the bottom of the sinus beneath the diaphragm and at great depth from the surface. Further and the patient died on September 1st, the conditions above mentioned being found on necropsy.

CASE vII. Suppurative Peritonitis, Tuberculous (?); ISpontaneous Opening : CASE VII. Suppurative Peritonitis, Tuberculous (9); Spontaneous Opening;
Drainage; Recovery. (Summary.)-Male, aged 8, very strumous in appear Drainage; Recovery. (Summary.)-Male, aged 8, very strumous in appear ance, was admitted to hospital July 30 th, 1893, very emaciated, with two sinuses at umbilicus discharging stinking pus, and with a collection of
pus in the left iliac and lumbar regions. There was a history of eiglit. pus in the left iliac and lumbar regions. There was a history of eight. weeks' illness, headache, pain in abdomen, vomiting, diarrhoea, swelling of the abdomen with œedema of its walls, and redness of the umbilicus, was drained on July 31st, and in a month the boy was well and rapidly gaining flesh. He is now in good health.

CASE VIII. Acute Tuberculous Peritonitis ; Drainage; Recovery. (Summary.)-Female, aged 16, admitted to hospital October 10th, 1892. with a history of two weeks' illness. At the time of operation there was fluid in the abdomen, which was rigid and tender, and the general condition was. markedly "typhoid." Pockets of viscid fluid were emptied, and tubercle was found widely spread

CASE perfect health. CASE 1X. Suppurative Tuberculous Peritonitis ; Drainage: Death. (Sum-
mary.)-Male, aged 20, admitted to hospital March 16th, 1893, for pain in mary.)-Male, aged 20, admitted to hospital March $16 \mathrm{th}, 1893$, for pain in fever some months previously. When operated on he was vomiting, his temperature was hectic, his belly distended and tender. A quantity of stinking pus and free gas was let out from the abdomen, but the patient. died of exhaustion on the fourth day. The necropsy sh

tuberculosis, but no perforation of the intestinal tract. formed; Death. (Summary.)-Female, aged 5, admitted to hospital July 20th, 1893, much emaciated, and with a history of a month's illness. The: abdomen was distended and tender, and contained a considerable amount of free fluid. The umbilicus was red, œedematous, and prominent. Several ounces of clear serous fluid were evacuated from various pockets, in September a fæcal fistula formed, and the child died in October.

The diagnosis of peritonitis is generally easy, but in a few cases it is extremely difficult. I have in mind a case of nephrolithotomy in the practice of a late colleague. Two. days after the operation the patient was regarded as suffering from severe peritonitis; the abdomen was distended and tender; there was absolute constipation; the pulse was quick and hard; vomiting was frequent, and blood was present in the vomit; the facial expression was bad to a degree; there was no suppression; yet at the necropsy not 
a trase of peritonitis was found, but an intense swelling and injestion of the mucous membrane of the stomach and upper part of the small intestine, with minute hæmorrhages into the mucous membrane.

The converse was seen in a patient of my own from whom a stenosed vermiform appendix was removed from an abscess crvity which to some extent had already infected the general peritoneal surfaces. In the first forty-eight hours after this operation there was marked improvement; but later the pulse quickened greatly, though it remained very soft; the face became flushed, not pinched; there was delirium; the abdomen was not distended; it was not tender when palpated, and the only conclusion one could arrive at was that the patient was dying of acute septicæmia, and that it was probably due to absorption from the abscess cavity which had been opened; at all events, there was nothing to justify a diagnosis of spreading peritonitis, and yet at the nocropsy a general purulent peritonitis was found.

l'o sum up: instead of the constipation generally present there may be diarrhœa; instead of a hard wiry pulse we may have a soft and dicrotic one; distension and tenderness may be absent. The most reliable signs in my experience are the steadily increasing frequency of the pulse, often with a low or falling temperature, and the facial appearance, this being either pinched and anxious or flushed, and this latter is usually associated with delirium. In many cases the phenomena are those of septicæmia, which mask and obscure the symptoms immediately due to the inflammatory process in the peritoneum. These latter are pain, shock, paresis of the bowel, and hard pulse, and are mainly produced through tho impression made on the widespread sympathetic plexuses of the abdomen by the inflammation which envelops them. It is worth noticing that the umbilicus seems to be the point at which inflammatory collections naturally find their way out, if they are general. In Case vir this actually happened, anid it was threatening in Cases Iv and $x$ at the time they were drained.

With regard to treatment, there is not much to be said which the notes of the cases do not convey. Incision in the middle line, irrigation, and drainage, is a simple procedure and carries with it but little risk, and it is a question whether it is resorted to as often as it should be. The profession is, perhaps, fully alive to its advantages when a very acute onset, such as is due to perforation, can be recognised, but when the commencement is less acute and the symptoms le.ss alarming in the early days, then I doubt if drainage is adopted as often as it is ealled for, in such cases, for instance, as Nos. $I$ and Ir. When the inflammatory collection is localised, and more especially if this be in the upper part of the alodomen, it is well not to do too much. Simple incision and drainage suffices; anything like forcible irrigation or searching about with the fingers by disturbing limiting adhesions is likely to do harm. In such cases as No. II, in which the second attack of peritonitis was due to perforation of the appendix, drainage by median incision is insufficient to meet the case, as there is constant reinfection of the peritoneum through the perforation. If a perforative focus is discovered it should be dealt with directly, and in the case of such a lesion as perforation of the appendix an incision directly down over this organ should be made for its removal, and at the same time median section should be performed for irrigation and drainage of the general cavity.

What the future of my patients who recovered may be is to some extent a matter for anxiety, although at the present time they are all perfectly well. The necropsy obtained after the second operation in Case II emphasises a danger that may always follow recovery from peritonitis, whether requiring operation or not. In this case a firm band of adhesion so constricted the rectum as to interfere with the proper emptying of the colon, and it is probable that had the patient recovered, he would eventually have suffered from intestinal obstruction.

I am much indebted to my colleague, Dr. Simon, for the readiness he sliowed to adopt early surgical measures in several of these cases which in the first instance were under his care.

Dr. IR. Cronin has been appointed a Justice of the Peace for the county of Meath.

\section{NOTES OF ABDOMINAL SURGICAL CASES.}

BY J. CRAWFORD RENTON, M.D.

Assistant to the Professor of Clinical Surgery in the University of Glasgow, Assistant Surgeon to the Western Infirmary, and Additional Examiner in Clinical Surgery in the

dinburgh.

Gastro-Enterostomy.

Is March, 1891, I showed to the Medico-Chirurgical Society of Glasgow a patient on whom I had performed the operation of gastro-enterostomy for pyloric tumour causing obstruction of the pyloric orifice and dilatation of the stomach. Full details of the case were published in the British Medical Journal for January 9th, 1892. Two years after the operation, which was performed on November 16th, 1890, the patient was again shown to the Society, quite well.

In a second case of gastro-enterostomy for dilatation of the stomach due to chronic fermentative dyspepsia, the operation was performed on February 6th, 1892.1 He is now quite well, and has no occasion to wash out his stomach, because the digested food gets out of it before fermentation takes place. The stomach is still dilated, but the organ is mechanically relieved by the anastomoses which has been formed between the stomach and jejunum or ileum.

The union in both the above cases was effected by means of Senn's plates of decalcified bone, which became absorbed in forty-eight hours, long enough time to permit of satisfactory union between the stomach and bowel.

The short time occupied in performing gastro-enterostomy is a very important factor in the success of the operation. Indeed, it may be laid down as a rule that in abdominal operations the shorter the time occupied in the doing of the operation and the warmer the patient is kept the better. This latter is generally effected by plenty of warm bags around the patient, or by a water bed filled with hot water, or by a large hollow tin pan on the operating table, which Professor Macewen kindly showed me in use in the Royal Infirmary.

Professor George Buchanan I was asked by Professor McCall Anderson to see C.D., who was a patient in his ward in the Western Infirmary during the summer of 1892. The medical report $I$ have received from Dr. Bishop, resident physician in Dr. Anderson's wards :

C. D., aged 24, was admitted on June 8th, 1892, complaining of repeated vomitings and great weakness, of two months' duration; previous health good. She was confined on April 18th, 1892, and since then has had frequent vomiting. Three days after delivery a lump formed in the abdomen. and was easily detected on admission. It was the size of an ostrich's egg, in the right ilio-lumbar region, and since her admission had increased in size without there being any pain. There was a distinct deposit of pus in the urine but no requency of micturition. On June 2ind Dr. Anderson and I saw her together, and we were quite satisfied examination of the urine, while showing pus, did not, when tested by Dr. Buchanan, show any tubercle bacilli, and even in the absence of pain we were hopeful that there might be a renal abscess caused by a calculus, although of course we were quite prepared for the possibility of an abscess opening into the kidney or ureter without a calculus. The patient was transferred to Professor Buchanan's ward, and in his absence, on June 28th, I cut down on the kidney by the posterior incision, and found it occupied by a large foetid abscess with a calculus in the ureter. The calculus was difficult to dislodge, and I regretted that I had not the bent forceps for the purpose which I believe Mr. Clarke of London advises. After extracting the calculus, the cavity was washed out, a drainage tube introduced, and the usual dressings applied. The caso progressed favourably, and on August 5 th she was dismissed well.

The point of interest in this case is the absence of pain. Generally there is severe pain in cases of calculus in the kidney, but from time to time we meet with complete absence of pain.

In a case in which Professor Buchanan had removed a stone from the bladder I removed one from the right kidney, and when he died, a year after, we found the left kidney full of calculi.

In another case which I dissected when a house-surgeon, and in which Dr. Heron Watson had successfully performed suprapubic lithotomy, I found the kidneys full of calculi. In this case there was pain in the renal region, but not to the extent that might have been expected. Consequently, we cannot dismiss the possibility of a stone in the kidney although there is no pain in the renal region, just as we cannot be certain that there is a stone although we have pain

${ }^{1}$ Fully described in the Glasgow Medical Journal for December, 1892. 